\title{
The response difference of forests to different drought
}

\author{
Hui luo ${ }^{1,2, a}$, Tao zhou ${ }^{1,2, b,{ }^{*}}$ \\ ${ }^{1}$ State Key Laboratory of Earth Surface Processes and Resource Ecology, Beijing Normal University, \\ Beijing, China \\ ${ }^{2}$ Academy of Disaster Reduction and Emergency Management, Ministry of Civil Affairs \& Ministry of \\ Education, Beijing, China \\ aluohui3377@163.com, ${ }^{b}$ tzhou@bnu.edu.cn, * Corresponding author
}

Keywords: short-term drought, prolonged drought, forests, SPEI, EVI.

Abstract: During the global warming, the duration of drought is increasing and the impact on forest ecosystems could be further intensified. It is always a concern that diverse forests respond to different duration of drought differently. In this research, the non-parametric Wilcoxon test was used to compare the forests' growth state in short-term drought (2001-2008) and prolonged drought (2009-2014), which based on the best time scale of SPEI that obtained by the correlation between MODIS EVI and SPEI. The results show that (1) the relationship between the June of EVI and the 5 months scale of SPEI (SPEI-5) is most close; (2) The growth state of two forests is similar in the short-term drought years, but natural forests are greater affected by prolonged drought than planted forests, and the percentage of planted forests with better growth state more than natural forests. The duration of droughts will increase continuously in the future, given that we suggest more attention should be paid to natural forests.

\section{Introduction}

During the global warming, the frequency, duration, intensity and scope of extreme weather events are increasing with the changes of global precipitation patterns [1,2]. The pressure on natural ecosystems is increasing with the increasing of the impact intensity, such as drought [3-5], and the response of forest ecosystems to drought is followed with great interest [6].

In recent decades, the area of planted forests has been ever increasing with the grown of human activity's influence [7], but whether will planted and natural forests respond to drought differently remains controversial, such as the adaptive capacity and the stability of ecosystems [8-10]. The similar research used the stem diameter, the net primary productivity and other indicators to compare the difference in response of planted and natural forests to drought [11-13]. But the research will serve the forests' growth state as the indicator to compare the difference in response of planted and natural forests to different duration of drought.

\section{Data and method}

\section{Area}

Yunnan Province is located in southwest China $\left(97.52^{\circ} \mathrm{E} \sim 106.18^{\circ} \mathrm{E}, 21.13^{\circ} \mathrm{N} \sim 29.25^{\circ} \mathrm{N}\right)$ (Fig. 1) [14], and various degree of drought occurred during 2001 to 2014 years [15,16]. The area of planted and natural forests contribute about $23.71 \%$ and $76.29 \%$ in Yunnan respectively, so the Yunnan province is an ideal place to research the difference in response of planted and natural forests to different drought.

\section{Data}

\section{MODIS data}

The map of planted and natural forests from the eighth forest inventory data of china (2009-2014)[17] was the latest and more precise forest of distribution information [18].

The forests' growth state will be characterized by the vegetation Index (MODIS EVI) that was got from the Land Processes Distributed Active Archive Center (2001-2014 years, 16 days, 500m). To 
improve the comparability, EVI was standardized to EVI standardized anomaly (ESA) based on the mean and standard deviation of EVI during non-drought years.

\section{Meteorological drought index}

The standardized precipitation evapotranspiration index (SPEI) will be selected to characterized the drought $[19,20]$, which was calculated based on the monthly average temperature and precipitation (1960-2014) from 30 meteorological stations in Yunnan province (Fig. 1). The SPEI calculation program was applied in this research comes from the DIGITAL.CSIC [21].

\section{Method}

\section{Choose the best time scale of SPEI}

In order to accurately characterize the drought, the best time scales of SPEI need to be determined [22,23]. Firstly, the relationship between EVI (1-12 months) and SPEI (1-12 months time scale) in all sites were established, and the number of sites that the relationship was passed the significance test will be counted. Finally, the best time scale that with the maximum of cumulative frequency was determined.

\section{Test the difference in response of planted and natural forests to drought}

The probability of the ESA less or more than two standard deviations was quite small, so the change in the forest area with ESA values less than -2 (more than 2) could represent the extent of forests suffering water stress (healthy growth) [18]. Then, the percentage of each intervals (ESA $<-2$ and ESA > 2) was summarized and compared by non-parametric Wilcoxon tests.

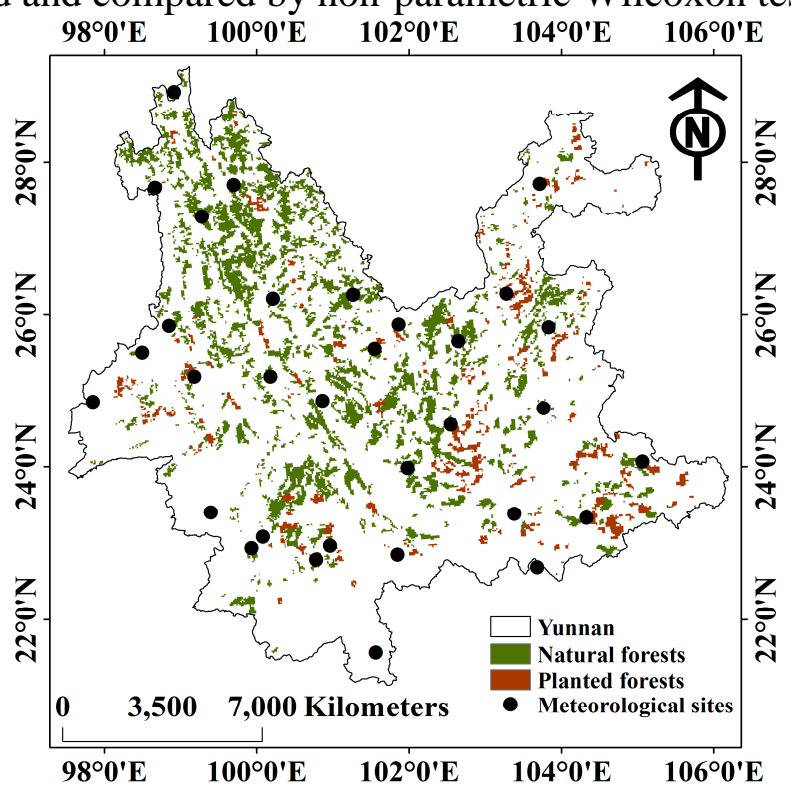

Figure 1. The area of research.

\section{Compare the best time scale of planted and natural forests}

Giving the correlation coefficient between June of EVI of planted forests and the 5, 8 months of SPEI, more than half of the sites $(55.56 \%)$ pass (the significant test $(\mathrm{p}<0.05)$. Consistently with the result of planted forests, the natural forests show the best relation between June of EVI and the 5 months scale of SPEI, and that sites pass the test significant account for $59.26 \%$. Therefore, to reduce the influence of time scales [9], the SPEI-5 and the ESA-6 were unified used as the indicators to characterize the intensity of drought and the changes of forests' growth state respectively.

\section{The difference in response of planted and natural forests to different drought}

\section{Comparison the sensitivity of planted and natural forests to drought}

The time trends in the SPEI-5 (Fig. 2a) show that various drought events (SPEI < -0.5) [24] occurred in 2005-2006, 2009-2014 years. So, the mean and standard deviation of EVI during 2001-2004 and 2007-2008 years were regarded as the computing base of ESA. According to the duration of drought, 
the research period was divided into 2001-2008 and 2009-2014 years, which presents short-term (2001-2008) and prolonged drought (2009-2014), and the difference in response of planted and natural forests to each drought were compared respectively.

The Figure 2 seems to be a similar and downward trend for SPEI-5 and ESA-6 from 2001 to 2014. The Pearson correlation coefficients of ESA- 6 and SPEI- 5 between planted and natural forests was $0.78(\mathrm{p}=0.001)$ and $0.84(\mathrm{p}<0.001)$ respectively. It reveals that planted and natural forests are sensitive to drought, but the natural forests are more sensitive to climate change than planted forests, because the correlation coefficient of natural forests is $7.33 \%$ larger than the planted forests.
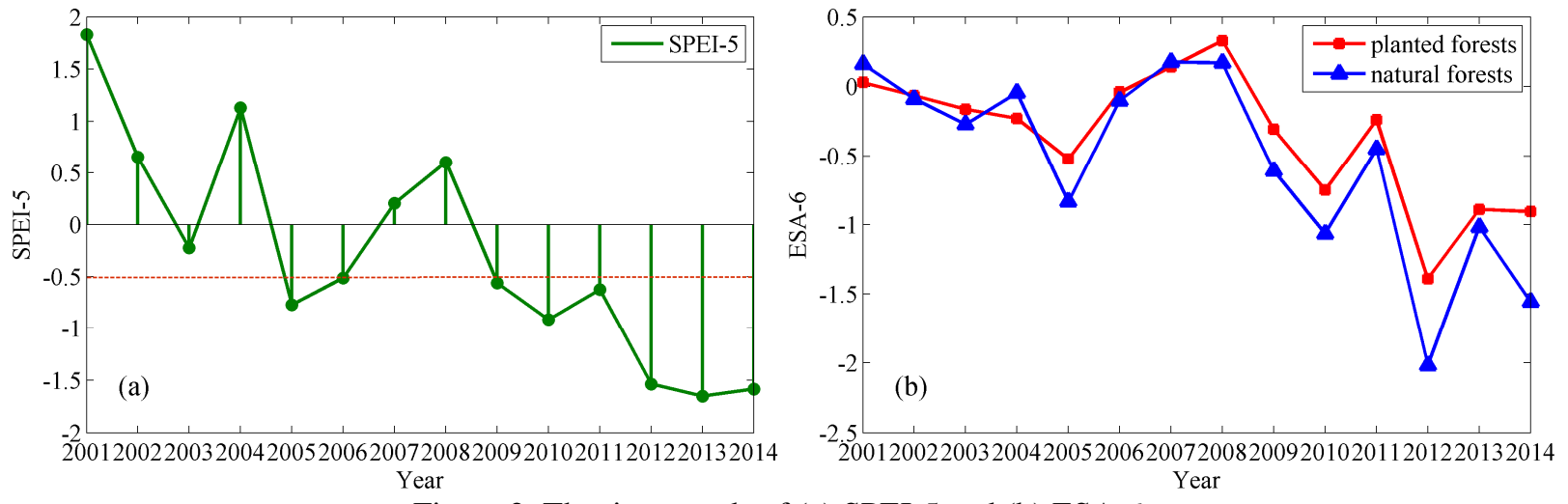

Figure 2. The time trends of (a) SPEI-5 and (b) ESA-6.

\section{The difference in response of planted and natural forests to different drought}

In the short-term drought years (2001-2008), the percentage of planted and natural forests can't pass the significance test (the $\mathrm{P}$ values is 0.093 and 0.069 respectively) (Table 1) in ESA-6 $<-2$ and ESA-6 > 2 intervals (Fig. 3), which reveals the consistent response of planted and natural forests to short-term drought.

In the prolonged drought years (2009-2014), the percentage of planted and natural forests pass the significant test in the ESA-6 $<-2$ and ESA-6 > 2 intervals, which shows a significant difference response in prolonged drought, what's more, the percentage of planted forests is lower than natural forests in the ESA-6 <-2 interval (Fig. 3) and greater than natural forests in the ESA-6 $>2$ interval (Fig. 3). That is, all forests are impacted by prolonged drought, but the growth state of natural forests affected by prolonged drought is greater than planted forests, and the percentage of planted forests with better growth state more than natural forests.

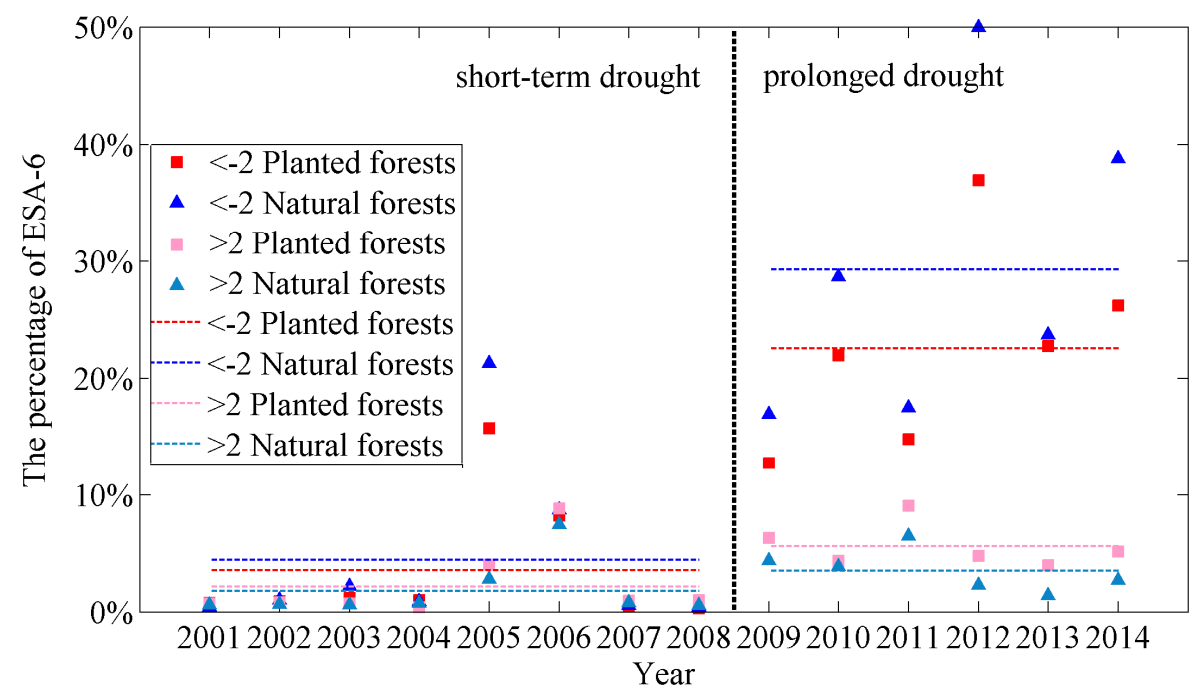

Figure 3. The difference in response of planted and natural forests to short-term drought (2001-2008) and prolonged drought (2009-2014). 
Table 1. The non-parametric Wilcoxon test between planted and natural forests in the short-term

\begin{tabular}{cccc}
\multicolumn{2}{c}{ drought (2001-2008) and prolonged drought $(2009-2014)}$. \\
\hline $\mathbf{2 0 0 1 - 2 0 0 8}$ & P value & N-negative & N-positive \\
\hline ESA-6<-2 & 0.093 & 2 & 6 \\
ESA-6>2 & 0.069 & 7 & 1 \\
\hline $\mathbf{2 0 0 9 - 2 0 1 4}$ & P value & N-negative & N-positive \\
\hline ESA-6 $<-2$ & 0.028 & 0 & 6 \\
ESA-6>2 & 0.028 & 6 & 0 \\
\hline
\end{tabular}

$\mathrm{N}$ is the difference between the number of planted and natural forests. $\mathrm{N}$-negative represents the numbers of the percentage of natural forests less than planted forests. N-positive represents the numbers of the percentage of natural forests more than planted forests.

\section{Discussions}

Consistent response of planted and natural forests to short-term drought, it is possible that two types forests unaffected by short-term drought, because forests may have conservative water and deeper root systems that can mitigate the effects of short water shortages on vegetation [25,26]. However, natural forests are greater affected by prolonged drought, which may be the long and intense drought could affected natural forests physiological structure [27] and greater than that of planted forests. And, the reason for the percentage of planted forests with better growth state more than natural forests in prolonged drought years, may be that planted forests have received more human management, such as being located in relatively moist environment with more irrigation [28], so the sensitivity of planted forests to water deficits will be reduced [11].

There were still some uncertainties in the study, because of some human errors in forest inventory process, and the limitation of materials, such as the spatial distribution of the drought intensity, and the errors caused by interpolation were unavoidable, thus, the provincial SPEI-5 was used for every forest type [18].

\section{Conclusions}

To compare the difference in response of forests to different drought, the short-term and prolonged drought was divided in the study. The results show that (1) June of EVI and the 5 months of SPEI (SPEI-5) is most close. (2) The response of planted and natural forests to short-term drought is consistent, while significant different response to prolonged drought, that is, natural forests are more strongly affected by prolonged drought than planted forests, and the percentage of planted forests with better growth state more than natural forests. (3) So more attention should be paid to natural forests.

\section{Acknowledgements}

This work was financially supported by the National Natural Science Foundation of China (No. 41571185), and the Fundamental Research Funds for the Central University (No. 2015KJJCB33).

\section{References}

[1]. V.H. Dale, L.A. Joyce, S. McNulty, R.P. Neilson: Science of the Total Environment. Sci. Vol. 262 (2000), P. 201-204.

[2]. B. Choat, S. Jansen, T.J. Brodribb, H. Cochard, S. Delzon, R. Bhaskar, S.J. Bucci, T.S. Feild, S.M. Gleason, U.G. Hacke, et al.: Nature. Sci. Vol. 491 (2012), P. 752-+.

[3]. T. Klein, D. Yakir, N. Buchmann, J.M. Gruenzweig: New Phytologist. Sci. Vol. 201 (2014), P. 712-716.

[4]. W.R.L. Anderegg, L. Plavcova, L.D.L. Anderegg, U.G. Hacke, J.A. Berry, C.B. Field: Global Change Biology. Sci. Vol. 19 (2013), P. 1188-1196.

[5]. Q. Wang, J. Wu, T. Lei, B. He, Z. Wu, M. Liu, X. Mo, G. Geng, X. Li, H. Zhou, et al.: Quaternary International. Sci. Vol. 349 (2014), P. 10-21. 
[6]. A. Jentsch, J. Kreyling, M. Elmer, E. Gellesch, B. Glaser, K. Grant, R. Hein, M. Lara, H. Mirzae, S.E. Nadler, et al.: Journal of Ecology. Sci. Vol. 99 (2011), P. 689-702.

[7]. D.F. Meason, W.L. Mason: Annals of Forest Science. Sci. Vol. 71 (2014), P. 239-253.

[8]. J.-C. Domec, J.S. King, E. Ward, A. Christopher Oishi, S. Palmroth, A. Radecki, D.M. Bell, G. Miao, M. Gavazzi, D.M. Johnson, et al.: Forest Ecology and Management. Sci. Vol. 355 (2015), P. 58-71.

[9]. C.D. Allen, A.K. Macalady, H. Chenchouni, D. Bachelet, N. McDowell, M. Vennetier, T. Kitzberger, A. Rigling, D.D. Breshears, E.H. Hogg, et al.: Forest Ecology and Management. Sci. Vol. 259 (2010), P. 660-684.

[10]. S.M. Pawson, A. Brin, E.G. Brockerhoff, D. Lamb, T.W. Payn, A. Paquette, J.A. Parrotta: Biodiversity and Conservation. Sci. Vol. 22 (2013), P. 1203-1227.

[11]. J. Zhou, Z. Zhang, G. Sun, X. Fang, T. Zha, S. McNulty, J. Chen, Y. Jin, A. Noormets: Forest Ecology and Management. Sci. Vol. 300 (2013), P. 33-42.

[12]. G. Vincent, H. de Foresta, R. Mulia: Forest Ecology and Management. Sci. Vol. 258 (2009), P. 1316-1322.

[13]. L.Wang, Y. Zhang, F. Berninger, B. Duan: Biogeosciences. Sci. Vol. 11 (2014), P. 5595-5606.

[14]. H. Luo, T. Zhou, H. Wu, S. Gao, Z. Li, P. P. Xu, L.Y. Cao: Jounal of Beijing Normal University (Natural Science). Sci. Vol. 52 (2016), P. 518-524 (in Cinese).

[15]. J. Yang, D. Gong, W. Wang, M. Hu, R. Mao: Meteorology and Atmospheric Physics. Sci. Vol. 115 (2012), P. 173-184.

[16]. X. Zhao, H. Wei, S. Liang, T. Zhou, B. He, B. Tang, D. Wu: Remote Sensing. Sci. Vol. 7 (2015), P. 14039-14054.

[17]. Information on http://www.forestry.gov.cn/main/65/content-659670.html.

[18]. H. Luo, T. Zhou, H. Wu, X. Zhao, Q.F. Wang, S. Gao, Z. Li: Remote Sensing. Sci. Vol. 8 (2016), P.

[19]. S.M. Vicente-Serrano, S. Begueria, J.I. Lopez-Moreno: Journal of Climate. Sci. Vol. 23 (2010), P. 1696-1718.

[20]. S.M. Vicente-Serrano, C.Gouveia, J. Julio Camarero, S. Begueria, R. Trigo, J.I. Lopez-Moreno, C. Azorin-Molina, E. Pasho, J. Lorenzo-Lacruz, J. Revuelto, et al.: Proceedings of the National Academy of Sciences of the United States of America. Sci. Vol. 110 (2013), P. 52-57.

[21]. Information on http://digital.csic.es/handle/10261/10002.

[22]. K. Huang, C. Yi, D. Wu, T. Zhou, X. Zhao, W.J. Blanford, S. Wei, H. Wu, D. Ling, Z. Li: Environmental Research Letters. Sci. Vol. 10 (2015), P.

[23]. Z. Li, T. Zhou, X. Zhao, K. Huang, S. Gao, H. Wu, H. Luo: International journal of environmental research and public health. Sci. Vol. 12 (2015), P. 7615-7634.

[24]. A.A. Paulo, R.D. Rosa, L.S. Pereira: Natural Hazards and Earth System Sciences. Sci. Vol. 12 (2012), P. 1481-1491.

[25]. U.G. Hacke, J.S. Sperry: Perspectives in Plant Ecology, Evolution and Systematics. Sci. Vol. 4 (2001), P. 97-115.

[26]. C.J. Willson, P.S. Manos, R.B. Jackson: American Journal of Botany. Sci. Vol. 95 (2008), P. 299-314.

[27]. S. Jonsson, B. Gunnarson, C. Criado: Geografiska Annaler Series a-Physical Geography. Sci. Vol. 84A (2002), P. 51-71.

[28]. Q. Guo, H. Ren: Global Ecology and Biogeography. Sci. Vol. 23 (2014), P. 1461-1471. 